\title{
Excess dietary iodine intake in long-term African refugees
}

\author{
Andrew J Seal ${ }^{1, *}$, Paul I Creeke ${ }^{1}$, Daniella Gnat ${ }^{2}$, Fathia Abdalla ${ }^{3}$ and Zahra Mirghani ${ }^{3}$ \\ ${ }^{1}$ Centre for International Child Health, Institute of Child Health, 30 Guilford Street, London WC1N 1EH, UK: \\ ${ }^{2}$ Deparment of Clinical Chemistry, Saint-Pierre Hospital, Brussels, Belgium: ${ }^{3}$ United Nations High Commissioner \\ for Refugees, Geneva, Switzerland
}

Submitted 11 January 2005: Accepted 14 June 2005

\begin{abstract}
Objective: To assess the iodine status of long-term refugees dependent on international food aid and humanitarian assistance.

Design: A series of cross-sectional two-stage cluster or systematic random sample surveys which assessed urinary iodine excretion and the prevalence of visible goitre. Salt samples were also collected and tested for iodine content by titration.

Setting: Six refugee camps in East, North and Southern Africa.

Subjects: Male and female adolescents aged 10-19 years.

Main results: The median urinary iodine concentration (UIC) ranged from 254 to $1200 \mu \mathrm{gl}^{-1}$ and in five of the camps exceeded the recommended maximum limit of $300 \mu \mathrm{gl}^{-1}$, indicating excessive iodine intake. Visible goitre was assessed in four surveys where it ranged from 0.0 to $7.1 \%$. The camp with the highest UIC also had the highest prevalence of visible goitre. The iodine concentrations in 11 salt samples from three camps were measured by titration and six of these exceeded the productionlevel concentration of 20 to $40 \mathrm{ppm}$ recommended by the World Health Organization (WHO), but were all less than $100 \mathrm{ppm}$.

Conclusions: Excessive consumption of iodine is occurring in most of the surveyed populations. Urgent revision of the level of salt iodisation is required to meet current WHO recommendations. However, the full cause of excessive iodine excretion remains unknown and further investigation is required urgently to identify the cause, assess any health impact and identify remedial action.
\end{abstract}

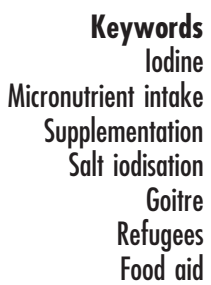

Iodine deficiency disease (IDD) is a major global cause of morbidity, mortality and impaired development. Universal salt iodisation has been extremely effective at reducing the burden of IDD and represents a major global public health success ${ }^{1}$. In Africa, great progress has been made towards the elimination of iodine deficiency, saving millions of children from its adverse affects, largely due to the increased household availability of iodised salt ${ }^{2}$. However, the relationship between iodine intake and the risk of thyroid disease is U-shaped, with both low and high iodine intakes associated with thyroid disease $\mathrm{e}^{3}$. The effect of the consumption of additional iodine is also dependent on the initial status of the population. In populations that are mildly deficient or replete, increases in dietary iodine may induce hypothyroidism, while in populations that were previously severely deficient, increased dietary iodine is associated with hyperthyroidism ${ }^{4,5}$.

Iodine-induced hyperthyroidism (IIH) is a serious condition that may in extreme cases lead to death, usually from heart-associated causes ${ }^{6}$. The increased susceptibility of iodine-deficient populations to IIH, particularly females over 40 years of age, results mainly from pre-existing multinodular thyroid disease and the presence of autonomous tissue in the thyroid gland ${ }^{7}$. Previous studies have shown that IIH can occur following the introduction of iodised salt and suggest that the risk of this adverse affect is related to the level of intake, although it is limited to a relatively short period of time after introduction ${ }^{1,8}$.

Previously deficient populations are particularly at risk of developing IIH if levels of intake are excessive. Optimal iodine intake is therefore important, but due to poor quality control at the production level and the high levels of fortification required by some African governments' legislation, which specifies up to 2.5 times the World Health Organization (WHO) recommendation, there is now a risk that populations which were previously severely deficient in iodine are now consuming an excess. Although it is accepted that the risks posed by deficiency greatly outweigh those associated with excess, it is still a concern that avoidable morbidity and mortality may be occurring as a result ${ }^{1}$. Underreporting of $\mathrm{IIH}$ is likely in developing countries where health services may be poorly developed and there is coexistence of predisposing iodine deficiency.

Within refugee populations that are dependent on food aid, iodine status is mainly dependent on the iodine content of the food ration. The World Food Programme 
(WFP) and the United Nations High Commissioner for Refugees (UNHCR) play key roles, in conjunction with national governments, in meeting the needs of these populations. Typically, basic food aid items such as cereals, pulses, oil, blended cereal foods and salt are supplied by WFP and complementary food items may be supplied by UNHCR. The iodine content of these commodities is expected to be low except in the case of salt or US-manufactured fortified blended cereal foods, which are fortified with iodine. A typical daily general ration of $2100 \mathrm{kcal}$ would be expected to contain between 150 and $200 \mu \mathrm{g}$ of iodine, a range consistent with optimal nutrition?. As part of a collaborative assessment of micronutrient status in the populations of six long-term African refugee camps, urinary iodine concentrations were measured to determine iodine status and assess the adequacy and safety of dietary intake.

\section{Methods}

Survey sites in Kenya, Uganda, Ethiopia, Algeria and Zambia were selected on the basis that they were longterm refugee camps (established between 1975 and 1993), dependent on international food aid and humanitarian service provision, and there was little significant information regarding the micronutrient status of the population. In addition, they were sites in which the United Nations (UN), government authorities and implementing agencies expressed interest and agreement for the proposed assessment. They were also required to have reasonable levels of access and security. The six surveys were carried out between March 2001 and July 2003, and the majority of survey subjects had spent all or most of their lives within these sites.

\section{Etbical approval}

Ethical approval for the surveys was obtained in each country from the relevant government and UN authorities responsible for refugee health and nutrition. Before survey initiation, community leaders were consulted in order to discuss any questions and reservations that they had on the process of surveying the population. Individual informed consent was obtained from all participants before samples were taken and, because of the particular situation of these populations, it was emphasised that refusal to participate in the surveys would have no negative impact on their entitlements to food aid or other services. No material benefits, other than feedback on their nutritional and health situation, were offered to encourage participation. Any subjects found to be suffering from malnutrition or infections were referred to the camp health facilities using local referral criteria.

\section{Sampling method}

Sample sizes were calculated for each of the individual camps and adolescents (10 to 19 years) were targeted.
A two-stage cluster sampling methodology was used in all camps except Nangweshi, where a systematic sampling procedure, based on house numbers, was used. Cluster and household selection was performed using standard WHO procedures ${ }^{10}$. Within each house all eligible subjects were selected for inclusion. If a dwelling contained more than one household, then all households were sampled. A household was defined as a group of people who shared resources such as shelter, water, food and income. Sitespecific definitions were produced for each camp after discussions with local stakeholders. Absentees were traced by revisiting the household on two separate occasions. If any subjects refused they were not replaced. Collection of age data was based on subject or parental recall.

\section{Goitre assessment}

Goitre was assessed by one member of each team who had received training in the recognition of visible goitre by the use of photo cards or subject observation. Palpable goitre was not assessed.

\section{Collection of urine}

Urine was collected from consenting adolescents in $100 \mathrm{ml}$ plastic collection cups or directly into collection tubes. The urine was transferred from the collection cups into a $10 \mathrm{ml}$ collection tube (Sarstedt Monovette ${ }^{\circledR}$ ) or $5 \mathrm{ml}$ cryovials (Nalgene $^{\circledR}$ ) and labelled with an identification number. Urine tubes were stored in vaccine boxes at 0 to $5^{\circ} \mathrm{C}$ until the end of the day, when they were transferred to a freezer for storage at -5 to $-15^{\circ} \mathrm{C}$. Samples were shipped on wet ice to London and forwarded to the analysis laboratory in Belgium.

\section{Analysis of urinary iodine}

Urine samples were analysed at the Department of Clinical Chemistry, Saint-Pierre Hospital, Brussels, Belgium. Analysis was performed on a fully automated Technicon Autoanalyser II. After strong acid digestion of the urine samples, the Sandell-Kolthoff reaction, catalysed by iodine, results in the reduction of ceric ammonium sulfate (yellow) to the colourless cerous form in the presence of arsenious acid ${ }^{11}$. A number of urine samples covering the whole concentration range and including several very high iodine values were re-analysed by the reference inductively coupled plasma-mass spectrometry method and yielded comparable results (regression equation: $\left.y=0.895 x+6.43 ; R^{2}=0.998\right)$.

\section{Collection of salt samples}

Eleven salt samples were collected using convenience sampling from markets, distribution points or households within the camps, or from adjacent markets used by refugees. The samples therefore consisted of a mixture of market-level and household-level samples. Salt samples were stored in airtight zip lock plastic bags at ambient 
temperature, and were analysed in London at the Institute of Child Health.

\section{Analysis of salt}

Iodine concentrations in salt samples were measured by titration $^{12}$. Iodine was released from an aqueous solution of the salt sample by the addition of dilute sulfuric acid and quantified by titration with a solution of sodium thiosulfate, using starch as the indicator. All salt samples were analysed in triplicate and those containing large crystals were ground with a pestle and mortar prior to titration.

\section{Data collection entry and analysis}

Data were entered and analysed using Epi Info 6.04d (Centers for Disease Control and Prevention, Atlanta, GA, USA), Excel 2000 (Microsoft Corporation, Redmond, WA, USA) and SPSS version 11 (SPSS Inc., Chicago, IL, USA). The Mann-Whitney test was used for testing for differences in the mean of non-normally distributed continuous variables, the chi-square test was used to test for differences in proportions, and the Pearson correlation coefficient was used to test for association between age and urinary iodine concentration (UIC). Significance was taken at the $P<0.05$ level. Means are expressed \pm one standard deviation and median values are given with ranges. A box plot diagram is used to compare the UIC between camps, where the median, upper $\left(\mathrm{P}_{75}\right)$ and lower $\left(\mathrm{P}_{25}\right)$ quartiles form the horizontal lines of the box. The vertical bars extend to the highest and lowest values, excluding outliers which are represented as individual circles. Outliers are defined as cases with values greater than 1.5 box lengths from the upper or lower edge of the box.

\section{Results}

Summary data on the sites selected for survey are provided in Table 1. Median levels of UIC ranged from 254 to $1170 \mu \mathrm{gl}^{-1}$ (Table 2). The distribution of UIC in each set of camp data was right-hand skewed. More males than females were sampled in Acholpii and Fugnido camps, and significantly more females were sampled in Kebribeya. However, no significant relationship was found between UIC and either sex or age in any of the camps.
The median UIC exceeded the upper limit of $300 \mu \mathrm{gl}^{-1}$ in five of the six camps and fell within the normal range only in one camp in Ethiopia (Fig. 1).

Visible goitre was assessed in four surveys where it ranged from 0 to $7.1 \%$ (Table 2). The camp with the highest UIC also had the highest prevalence of goitre, and there appears to be a dose-response relationship between the median level of UIC and the prevalence of visible goitre. The presence of visible goitre suggests that the ranges of iodine concentrations, ingested by these populations, are having a measurable effect on thyroid function.

No public health programmes were practised in any of the camps which involved the iodisation of water supplies or the systematic widespread use of iodine-containing disinfectants or drugs. Food rations were normally supplied by the WFP and typically consisted of a cereal, pulses, cooking oil, salt and sometimes fortified blended foods. Iodised salt and some types of fortified blended foods were therefore the only likely significant sources of dietary iodine, although market trade, agricultural production and exchange did lead to a degree of diet diversification at most sites.

The iodine concentrations of 11 salt samples, from three camps (Kakuma, $n=3$; Acholpii, $n=6$; and Fugnido, $n=2$ ), were measured by titration and ranged between 6 and $86 \mathrm{ppm}$, with a mean of $44.4 \pm 25.1 \mathrm{ppm}$. Six of the samples exceeded the WHO-recommended productionlevel concentration of 20 to $40 \mathrm{ppm}$, but all were less than $100 \mathrm{ppm}$. Salt rations distributed by WFP normally comprise $5-10$ g person $^{-1}$ day $^{-1}$, so, in the camps where samples were collected, this was calculated to contribute up to $440 \mu \mathrm{g}$ of iodine per person per day.

\section{Discussion}

This paper is the first report of a systematic, multi-site assessment of iodine status in long-term African refugees. It shows that, according to recommended values, iodine excretion is excessive and that iodine intakes are likely to be at levels that carry risks of adverse health effects ${ }^{1,13}$. In addition, where goitre was assessed, we found the highest prevalence in the camps with the highest median UIC. Previous reports have documented the occurrence of goitre, induced by excess iodine, at levels comparable to

Table 1 Summary information on survey sites

\begin{tabular}{lclcl}
\hline Refugee camp & Date camp established & Survey date & Population size & Main countries of origin \\
\hline Kenya - Kakuma & 1992 & March 2001 & 72459 & East Africa and the Horn \\
Uganda - Acholpii & 1993 & June 2001 & 21500 & Sudan \\
Ethiopia - Fugnido & 1993 & October 2001 & 28088 & Sudan \\
Ethiopia - Kebribeya & 1991 & November 2001 & 11634 & Somalia \\
Algeria - Tindouf & 1975 & September 2002 & 155430 & Western Sahara \\
Zambia - Nangweshi & 1992 & July 2003 & 15000 & Angola \\
\hline
\end{tabular}


Table 2 Urinary iodine concentration (UIC) and the prevalence of goitre in adolescents (10-19 years) from each refugee camp

\begin{tabular}{|c|c|c|c|c|c|c|c|c|}
\hline \multirow[b]{2}{*}{ Refugee camp } & \multirow[b]{2}{*}{$n$} & \multirow[b]{2}{*}{ Mean age (years) } & \multirow[b]{2}{*}{ Male (\%) } & \multicolumn{3}{|c|}{ UIC $\left(\mu g I^{-1}\right)$} & \multicolumn{2}{|c|}{ Visible goitre $^{*}$} \\
\hline & & & & Median & Min & Max & $n$ & Prevalence (\%) \\
\hline Kenya - Kakuma & 191 & - & - & 620 & 38 & 2380 & - & N/A \\
\hline Uganda - Acholpii & 176 & 15.6 & 63.1 & 726 & 150 & 3400 & 723 & $0.4(0.0-1.2)$ \\
\hline Ethiopia - Fugnido & 136 & 14.6 & 61.8 & 1074 & 74 & 8400 & 157 & $1.3(0.1-7.9)$ \\
\hline Ethiopia - Kebribeya & 172 & 14.0 & 36.6 & 254 & 14 & 2020 & - & $\mathrm{N} / \mathrm{A}$ \\
\hline Algeria - Tindouf & 115 & 13.6 & 54.8 & 1170 & 62 & 3900 & 589 & $7.1(3.6-10.7$ \\
\hline Zambia - Nangweshi & 105 & 13.3 & 54.3 & 570 & 65 & 6630 & 213 & 0.0 \\
\hline
\end{tabular}

${ }^{*}$ Prevalence given with $95 \%$ confidence intervals in parentheses; N/A - not assessed.

† Age and sex data were not available due to theft of data files prior to final analysis.

those seen in the camps within this study ${ }^{14,15}$. The full implications of our finding need to be investigated urgently.

A previous multi-site study ${ }^{16}$ was carried out between 1995 and 1996 in seven African countries amongst resident populations with access to iodised salt. This showed that iodine deficiency was no longer present in any of the areas surveyed in the seven countries. It also showed that in most of the areas excess iodine was now consumed and UIC were in some cases far in excess of the normal upper limit of $200 \mu \mathrm{gl}^{-1}$, with an individual value in Tanzania of $11200 \mu \mathrm{gl}^{-1}$. The results reported herein for refugee populations are therefore qualitatively similar but the median values are markedly higher. As typically found in most UIC surveys, the distributions of the values for each camp were right-hand skewed ${ }^{16}$. However, the results of both the seven-country study and this paper contrast markedly with the lower median values reported for most African countries ${ }^{2}$.

As a result of the seven-country study, WHO, the United Nations Children's Fund and the International Council for Control of Iodine Deficiency Disorders produced revised

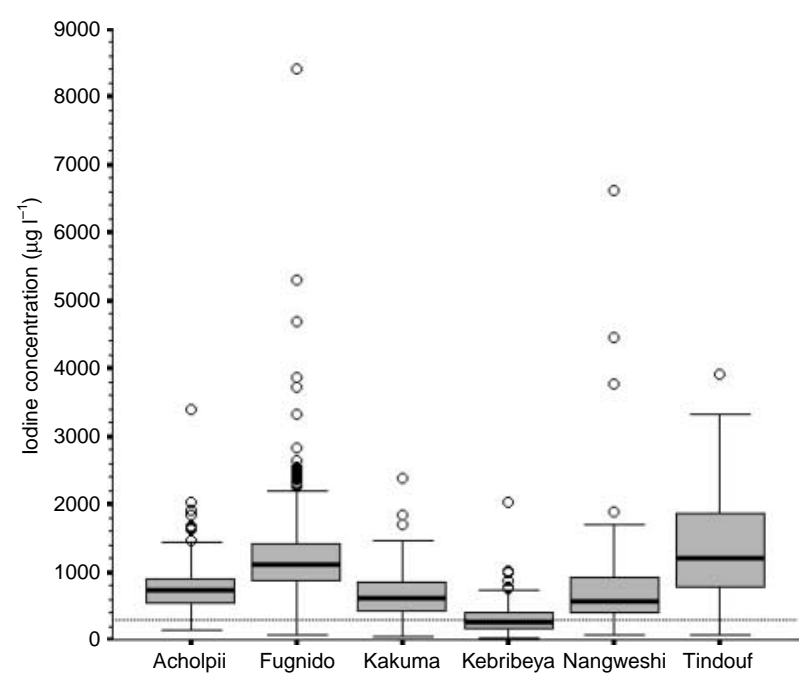

Fig. 1 Box plot presentation of urinary iodine concentrations from adolescents (10-19 years) in different camps. The upper safe limit of $300 \mathrm{\mu gl}^{-1}$ for median excretion is shown with a dotted line guidelines that recommended a reduction in the level of salt iodisation, at production, to between 20 and $40 \mathrm{ppm}$, and emphasised the need for strict monitoring procedures ${ }^{17}$. However, current legislation for the production of iodised salt in the countries in which the refugees are now situated has not yet been amended to take into account these new guidelines ${ }^{2}$. In refugee and emergency food aid operations, where iodine-deficient populations may rapidly and radically change diets, particular care should be paid to optimise the level of iodine consumption to minimise risks of both inadequate and excessive intake.

The WHO population safe level of intake for emergencyaffected populations, and the US recommended daily allowance for adult men and women, is $150 \mu \mathrm{g}$ daily ${ }^{10,18}$. This compares with the US Tolerable Upper Intake Level $(\mathrm{UL})^{18}$, which has been set at $1100 \mu \mathrm{g} \mathrm{day}^{-1}$, or a UK Guidance Level ${ }^{19}$ of $940 \mu \mathrm{g} \mathrm{day}^{-1}$. The European Union ${ }^{20}$ sets a lower UL of $600 \mu \mathrm{g}$ day $^{-1}$ for adults and notes that in populations where iodine deficiency pre-exists, the UL should be set at $500 \mu \mathrm{g} \mathrm{day}^{-1}$. We have estimated the likely dietary intake from salt based on the measurement of a small number of salt samples and the amount of salt normally distributed in the food aid ration. This estimated amount is about three times the WHO safe level of intake but below the UL. It would be likely, however, to result in urine excretion levels in excess of the upper recommended median limit. However, by itself, it cannot account for the very high median levels found in our surveys or the extremely high concentrations found in some individuals.

To account for our findings we have to consider the following possibilities: salt intakes in these populations are considerably higher than assumed; the presence of salt iodised at a higher level than the samples we tested; the consumption of significant quantities of iodine in other foodstuffs; or high levels of naturally occurring iodine in drinking water. The last possibility seems a likely candidate in the Tindouf camp, which is located in the Sahara desert. In conclusion, while the fortification level of salt supplied to these populations appears to be excessive and should be reduced immediately to the levels recommended by $\mathrm{WHO}$, the entire cause of this excessive 
iodine excretion remains unclear. However, further investigation, including biochemical screening for IIH using serum thyroid-stimulating hormone, free triiodothyronine and free thyroxine, is required urgently to identify the cause, assess any health impact and identify remedial action.

\section{Acknowledgements}

This work was funded by the UNHCR with a grant from the United Nations Fund for International Partnership, and the Micronutrient Initiative, Ottawa, Canada through the financial assistance of the Government of Canada through the Canadian International Development Agency. We would like to thank Professor François Delange and Tina van den Briel (Senior Technical Adviser, WFP) for discussion of the draft.

Many local and international staff from collaborating non-government organisations, government and UN agencies participated in the planning and implementation of these surveys and without their collaboration and assistance this work would not have been possible. Thanks are also due to the refugee communities for their co-operation during the surveys.

\section{References}

1 Delange F, De Benoist B, Pretell E, Dunn JT. Iodine deficiency in the world: where do we stand at the turn of the century? Thyroid 2001; 11: 437-47.

2 International Council for the Control of Iodine Deficiency Disorders. IDD Newsletter 2003; 19: 1-6.

3 Laurberg P, Bulow Pedersen I, Knudsen N, Ovesen L, Andersen S. Environmental iodine intake affects the type of nonmalignant thyroid disease. Thyroid 2001; 11: 457-69.

4 Markou K, Georgopoulos N, Kyriazopoulou V, Vagenakis AG. Iodine-induced hypothyroidism. Thyroid 2001; 11: 501-10.

5 Stanbury JB, Ermans AE, Bourdoux P, Todd C, Oken E, Tonglet R, et al. Iodine-induced hyperthyroidism: occurrence and epidemiology. Thyroid 1998; 8: 83-100.

6 Dunn JT, Semigran MJ, Delange F. The prevention and management of iodine-induced hyperthyroidism and its cardiac features. Thyroid 1998; 8: 101-6.

7 Corvilain B, Van Sande J, Dumont JE, Bourdoux P, Ermans AM. Autonomy in endemic goiter. Thyroid 1998; 8: 107-13.
8 Gomo ZA, Allain TJ, Matenga JA, Ndemere B, Wilson A, Urdal P. Urinary iodine concentrations and thyroid function in adult Zimbabweans during a period of transition in iodine status. American Journal of Clinical Nutrition 1999; 70: 888-91.

9 Institute of Child Health. NutVal 2004 - Excel Spreadsheet Application, version 1.0. London: Institute of Child Health, 2004.

10 World Health Organization (WHO). The Management of Nutrition in Major Emergencies. Geneva: WHO, 2000.

11 Riley M, Gochman N. A fully automated method for the determination of serum protein-bound iodine. Presented at Technicon Symposium, Tarrytown, NY, 1964.

12 United Nations Children's Fund (UNICEF) ROSCA. The Use of Iodised Salt in the Prevention of Iodine Deficiency Disorders - A Handbook of Monitoring and Quality Control. New Delhi: UNICEF ROSCA, 1998.

13 International Council for Control of Iodine Deficiency Disorders/United Nations Children's Fund/World Health Organization (WHO). Assessment of Iodine Deficiency Disorders and Monitoring their Elimination. A Guide for Programme Managers. WHO/NHD/01.1. Geneva: WHO, 2001.

14 Mu L, Chengyi Q, Qidong Q, Qingzhen J, Eastman C, Collins $\mathrm{J}$, et al. Endemic goitre in central China caused by excessive iodine intake. Lancet 1987; 330: 257-9.

15 Jooste PL, Weight MJ, Kriek JA, Louw AJ. Endemic goitre in the absence of iodine deficiency in schoolchildren of the Northern Cape Province of South Africa. European Journal of Clinical Nutrition 1999; 53: 8-12.

16 Delange F, De Benoist B, Alnwick D. Risks of iodine-induced hyperthyroidism after correction of iodine deficiency by iodized salt. Thyroid 1999; 9: 545-56.

17 World Health Organization (WHO)/United Nations Children's Fund/International Council for Control of Iodine Deficiency Disorders. Recommended Iodine Levels in Salt and Guidelines for Monitoring their Adequacy and Effectiveness. WHO/NUT/96.13. Geneva: WHO, 1996.

18 Food and Nutrition Board, Institute of Medicine. Dietary Reference Intakes for Vitamin A, Vitamin K, Boron, Chromium, Copper, Iodine, Iron, Manganese, Molybdenum, Nickel, Silicon, Vanadium, and Zinc. Washington, DC: National Academy Press, 2001.

19 Expert Group on Vitamins and Minerals. Safe Upper Levels for Vitamins and Minerals. London: Food Standards Agency, 2003.

20 European Commission. Opinion of the Scientific Committee on Food on the Tolerable Upper Intake Level of Iodine. SCF/CS/NUT/UPPLEV/26 Final. Brussels: European Commission, 2002. 